\title{
A study to assess the quality of life (OOL) of patients suffering from tinea corporis attending dermatology OPD of a tertiary care centre of Eastern India
}

\author{
Kumar Das N. ${ }^{1}$, Das S. ${ }^{2 *}$ \\ DOI: https://doi.org/10.17511/ijmrr.2019.i06.08 \\ ${ }^{1}$ Nirmalya Kumar Das, Tutor, Department of Dermatology, Venereology and Leprosy, NRS Medical College, Kolkata, West Bengal, India. \\ 2* Suchibrata Das, Assistant Professor, Department of Dermatology, Venereology and Leprosy, NRS Medical College, Kolkata, West Bengal, \\ India.
}

Background: A huge number of patients in our country are affected by Tinea Corporis (TC). The number of patients affected by dermatophytosis has increased by a large extent in the last 4 to 5 years. The quality of life in TC patients can be affected by various factors including the disease morbidity, duration of disease, social \& demographic factors. Aims and Objectives: The aim of the study is to find out the effect of TC on the quality of life of the affected patients \& along with that to assess whether there is some association of this effect on quality of life with some demographic \& clinical factors. Methods: The effect on quality of life of 328 patients affected by TC who attended the Dermatology outpatient's department of NRS Medical College was assessed using the Dermatology Life Quality Index (DLQI) questionnaire. Results: 12 (3.658\%) of the patients had an extremely large effect on quality of life. There was a very large effect on the QOL of 121 (36.890\%) patients. There was moderate effect on $134(40.853 \%)$ of the patients. There was a small effect on $59(17.987 \%)$ of the patients. $2(0.609 \%)$ patients had no effect on their QOL. Duration of disease \& body surface area involved have significant impacts on QOL. Conclusion: The quality of life is adversely affected by TC. Early detection \& treatment of the disease is very important. Steps must be taken to increase awareness about the disease among the general population.

Keywords: Tinea Corporis, Quality of life, Dermatology Life Quality Index (DLQI)

Corresponding Author

Suchibrata Das, Assistant Professor, Department of Dermatology, Venereology and Leprosy, NRS Medical College, Kolkata, West Bengal, India. Email: suchibratadas@yahoo.com
How to Cite this Article

To Browse

Das NK, Das S. A study to assess the quality of life (QOL) of patients suffering from tinea corporis attending dermatology OPD of a tertiary care centre of Eastern India. Int J Med Res Rev. 2019;7(6):496503.

Available From

https://ijmrr.medresearch.in/index.php/ijmrr/article/

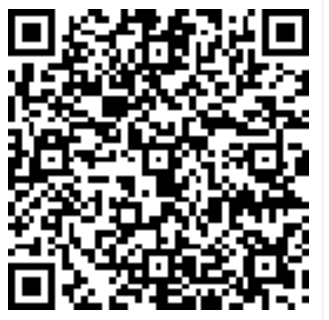
view/1103

Manuscript Received 2019-12-10

Conflict of Interest No
Review Round 2 2019-12-26 Yes
Ethical Approval

Review Round 3

Accepted
$2019-12-29$ 2019-12-20

Nil
Plagiarism X-checker $8 \%$
Note an Open Access article licensed under a Creative Commons Attribution 4.0 International License https://creativecommons.org/licenses/by/4.0/ unported [CC BY 4.0]. 


\section{Introduction}

WHO has defined Quality Of Life (QOL) as the "individual's perception of their position in the context of culture \& value systems in which they live $\&$ in relation to their goals, expectations, standards \& concerns" [1]. The concept of QOL includes physical activities, occupational opportunities, social relationships and psychological well being [2].

TC is dermatophytosis of the skin excluding palms, soles and groins. Species of Tricmophyton, Epidermophyton \& Microsporum are the causative organisms of TC mostly. The usual lesions are annular. The centre is clear while the border of the lesions are erythematous, scaly or vesicular.

The lesions are generally extremely itchy. QOL of the patients can be affected because the lesions are itchy. QOL can be affected also because the lesions on visible parts of the body can lead to social discrimination. Many people in our society suffer from poverty, illiteracy, \& unhygienic

Conditions. Lots of people have poor standard of living and this disease can have further adverse effects on their quality of life. There was another possibility that people living under such adverse conditions may not perceive the disease to cause much appreciable change to their quality of life.

A huge number of people of our country are now affected by the disease TC [3]. The prevalence of superficial dermatophytosis has increased to a great extent in the last 4 to 5 years. [3] A study conducted in Mangalore also found that the number of patients affected by superficial dermatophytosis has increased alarmingly in the last few years [4].

Many of these patients do not take proper and regular treatment. So the disease persists and naturally affects the QOL of the patients. Another serious problem is that the dermatophytes are getting resistant to the commonly used drugs.

However, there are not many studies which have assessed the effect of TC on the QOL of the patients. The present study assessed the impact of $\mathrm{TC}$ on the QOL of the patients attending the Dermatology outpatient's department of $N R S$ Medical College \& Hospital, Kolkata, West Bengal.

The present have used the Dermatology Life Quality Index (DLQI) [5] which has been validated in Hindi, English and Bengali for assessing the QOL of the patients.
The present study also assessed the effect of age, gender of the patient, duration of the disease \& extent of body surface area involvement on the quality of life.

\section{Materials and Methods}

Type of study: This study is a questionnaire-based cross-sectional study. All data were recorded at first visit and no follow up data was collected.

Sampling methods: Every patient attending the OPD \& fulfilling the inclusion criteria was included in the study.

Inclusion criteria: All patients presenting with the signs and symptoms of TC were detected and among them those who were willing to participate in the study through a written informed consent, were included in the study.

Exclusion criteria: TC patients with any other debilitating disease, psychiatric problems and other medical conditions which may have an impact on QOL were not included in the study.

Data collection procedure: Age, Gender, Duration of disease \& Extent of Body surface area involved were recorded in the case record form.

Duration of disease was calculated in weeks.

Body Surface Area involvement was calculated using the ' Rule of palm '. Total palmar surface of palm and five digits of the patient was together taken equivalent to $1 \%[6]$.

Body Surface Area (in \%) involvement was considered in groups as follows-

$\leq 2,3$ to $10,>10[6]$

The present study have used the Dermatology Life Quality Index (DLQI)[5] for assessing the QOL in TC patients.

Dermatology Life Quality Index or DLQI [5] was developed by Professor A Y Finlay and colleagues. It is one of the most used tools for assessing the Quality of Life. It has 10 simple questions.

Patients attending the OPD were screened for TC. Written informed consent were taken from the patients. The findings were recorded in a case record form. The DLQI Questionnaire was clearly explained to the patients. The patients were then asked to answer the questions. The DLQI Scores were then calculated, compared \& evaluated. 
Scoring System: The scoring of each question is as follows:

Not at All / Not relevant - 0

A Little - 1

A Lot -2

Very Much -- 3

The DLQI is calculated by summing the score of each question. The minimum DLQI score can be 0 \& the maximum can be 30 .

The higher the score, the more is the QOL impaired.

The interpretation DLQI score is as follows:

- $0-1$-- no effect

- 2-5 -- small effect

- 6-10 -- moderate effect

- 11-20 -- very large effect

- 21-30 -- extremely large effect

Data Analysis: Data were analysed by appropriate statistical tests.

\section{Results}

The total number of patients was 328 . There was no effect on the QOL of $2(0.609 \%)$ patients. There was a small effect on $59(17.987 \%)$ and moderate effect on $134(40.853 \%)$ of the patients. The disease had a very large effect on the QOL of $121(36.890 \%)$ patients. $12(3.658 \%)$ patients had an extremely large effect (Table-1)

There were 154 [46.951\%] male patients and 174 [53.048\%] were female patients. TC had no effect on the QOL of $1(0.649 \%)$ of the male patients. There was a small effect on 30 (19.480\%), moderate effect on $66(42.857 \%)$, very large effect on $51(33.116 \%)$ and extremely large effect on the QOL of $6(3.896 \%)$ of the male patients. TC had no effect on the QOL of $1(0.574 \%)$ of the female patients. There was small effect on $29(16.666 \%)$ of the female patients. The disease had a moderate effect on $68(38.080 \%)$ and very large effect on the QOL of $70(40.229 \%)$ of the female patients. There was extremely large effect on the QOL of 6 $(3.448 \%)$ of the female patients (Table- 1 ).

Table-1: Effect on quality of life.

\begin{tabular}{|l|l|l|l|}
\hline Effect On QOL & \multicolumn{1}{|c|}{$\begin{array}{c}\text { Number \& percentage of } \\
\text { patients (total - 328) }\end{array}$} & \multicolumn{1}{|c|}{$\begin{array}{c}\text { Number \& percentage among male patients } \\
\text { (total-154[46.951\%]) }\end{array}$} & $\begin{array}{c}\text { Number \& percentage among female patients } \\
\text { (total- 174[53.048\%]) }\end{array}$ \\
\hline No Effect & $2(0.609 \%)$ & $1(0.649 \%)$ & $1(0.574 \%)$ \\
\hline Small Effect & $59(17.987 \%)$ & $30(19.480 \%)$ & $29(16.666 \%)$ \\
\hline Moderate Effect $134(40.853 \%)$ & $66(42.857 \%)$ & $68(38.080 \%)$ \\
\hline $\begin{array}{l}\text { Very Large } \\
\text { Effect }\end{array}$ & $121(36.890 \%)$ & $51(33.116 \%)$ & $70(40.229 \%)$ \\
\hline $\begin{array}{l}\text { Extremely } \\
\text { Large Effect }\end{array}$ & $12(3.658 \%)$ & $6(3.896 \%)$ & $6(3.448 \%)$ \\
\hline
\end{tabular}

Mean DLQI Score among the 328 patients was $10.0762 \pm 5.0129$. The Median Score was 9. The Mean DLQI score among the male patients was $9.7597 \pm 5.1106$. The Median DLQI Score of the male patients was 8 . Mean DLQI Score among the female patients was $10.3200 \pm 4.9318$. The Median DLQI score of the female patients was 10 . Among the 328 patients included in the study the youngest patient was 17 years and the oldest one was 82 years old. Table 2 shows that Age has no statistically significant correlation with DLQI Score. The Mean DLQI Score is higher in case of females compared to males. However, it is also seen in Table 2 that there is no statistically significant correlation between Gender and DLQI score.
Table-2: Association of demographic features with DLQI score

\begin{tabular}{|l|l|l|l|}
\hline Parameter & Correlation coefficient $95 \%$ confidence interval & P value \\
\hline Age & 0.02960 & -0.07895 to 0.1374 & $\mathrm{P}=0.5933$ \\
\hline Gender & -0.05949 & -0.1667 to 0.04913 & $\mathrm{P}=0.2828$ \\
\hline
\end{tabular}

Table 3 shows that there is a statistically significant positive correlation between Body Surface Area Involvement and Duration of Disease with DLQI Score. This proves that with increase in body surface area involvement the DLQI score is increasing which means that QOL is more impaired. Similarly, with increase in duration of disease the DLQI score is increasing \& QOL is more adversely affected. 
Table-3: Association of some clinical aspects with DLQI score

\begin{tabular}{|l|l|l|l|}
\hline \multicolumn{1}{|c|}{ Parameter } & \multicolumn{1}{|c|}{$\begin{array}{c}\text { Correlation } \\
\text { coefficient }\end{array}$} & $\begin{array}{c}95 \% \text { confidence } \\
\text { interval }\end{array}$ & P value \\
\hline $\begin{array}{l}\text { Body surface area } \\
\text { involvement }\end{array}$ & 0.9133 & 0.8933 to 0.9296 & $\mathrm{P}<0.0001$ \\
\hline Duration of disease & 0.6909 & 0.6298 to 0.7436 & $\mathrm{P}<0.0001$ \\
\hline
\end{tabular}

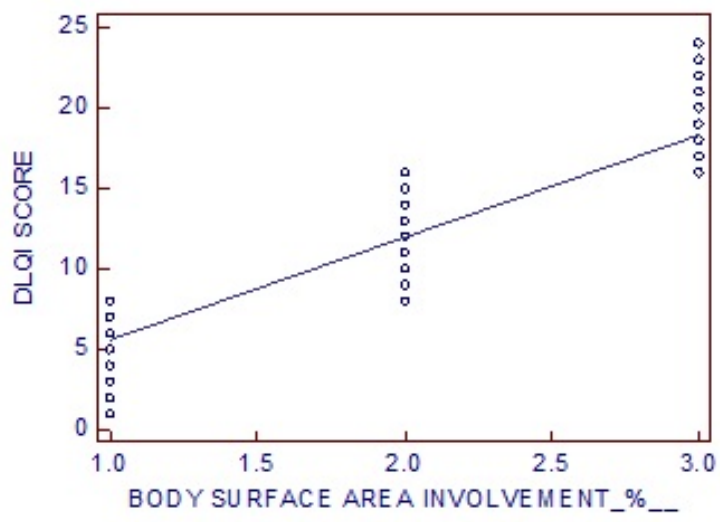

Fig-1: Scatter diagram and regression line showing increase in DLQI score with increase in body surface area involvement.

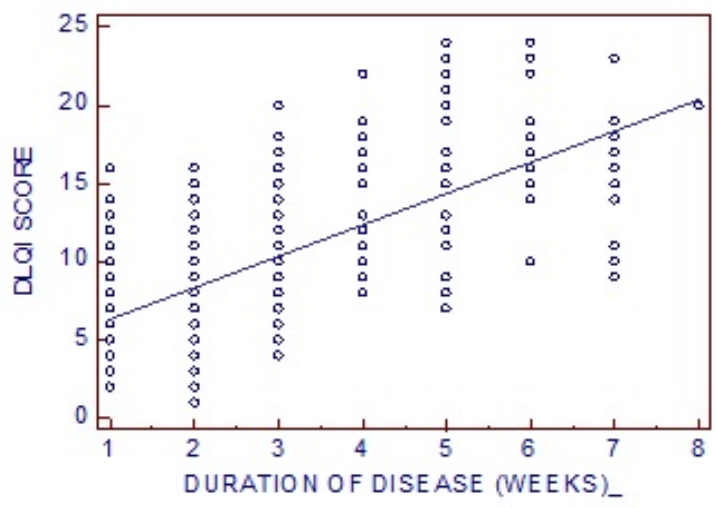

Fig-2: Scatter Diagram and regression line showing increase in DLQI score with increase in duration of disease.

Figure 1 and Figure II depicts Scatter Diagram and Regression line showing increase in DLQI Score with increase in Body Surface Area and Increased Duration of Disease, respectively. Dermatophytes are the most common agents of superficial fungal infections. It is widespread in tropical countries like India [7]. Dermatophytes infect keratinised tissues like skin, hair \& nails [8].

Dermatophytes can be classified into Trichophyton, Epidermophyton \& Microsporum according to genera [9].

\section{Discussion}

Dermatophytes can be anthropophillic, zoophilic, and geophilic depending on the mode of transmission [9]. Dermatophyte infection can be divided clinically according to the affected site [9]. Tinea Corporis (TC) is dermatophyte infection of the body. The most common symptom that the patients of dermatophyte infection suffer is pruritus [10]. Pruritus when severe $\&$ prolonged adversely affects the QOL [10]. Visible lesions also lead to embarrassment \& reduction in QOL [10]. The longdrawn treatment \& the associated costs also are issues which have a negative impact on QOL [10].

Dermatophytosis is considered chronic if the duration of disease is $>6$ months to 1 year [11] The disease is now considered as recurrent if the symptoms have recurred within 6 weeks of stopping adequate antifungal therapy with at least two such episodes in 6 months [12].

Several studies have shown that TC is a very common manifestation of dermatophyte infection in our country $[13,14,15,16]$. Trichophyton Rubrum has been found to be the commonest causative agent in many studies [17]. The present study included a total of 328 patients. A study conducted by Patro $\mathrm{N}$ et al included 294 patients [10]. Another study conducted by Rajashekar TS et al had a total of 186 patients [18]. In the present study there were 154 [46.951\%] males and 174 [53.048\%] females. The study by Patro $\mathrm{N}$ et al had 138 (46.93\%) males and $156(53.06 \%)$ females [10].

There are other studies where there are more male patients than female patients. The study population in the study conducted by Rajasekhar TS et al included 137 (73.65\%) males and 49 females (26.34\%) [18]. The mean \& standard deviation of the DLQI score among the total 328 patients in the present study was $10.0762 \pm 5.0129$. The mean \& standard deviation of the DLQI score among the 174 female patients in the present study was $10.3200 \pm 4.9318$. The mean \& standard deviation of the DLQI score among the 154 males was $9.7597 \pm 5.1106$.

The total mean \& standard deviation of the DLQI score in a study by Rajashekar TS et al was $12.79 \pm 5.9567$ [18]. The mean \& standard deviation of the DLQI score among the female patients and male patients respectively were $11.61 \pm 5.9470$ and $13.21 \pm 5.9244$ in that same study [18]. 
In the present study there was no correlation between age and DLQI score. However, in the study by Rajashekar TS et al, the mean DLQI score increased as age of the patients with TC increased [18]. Similar increase in DLQI score with increase in age has been observed in other studies regarding other dermatoses like alopecia areata, acne and psoriasis $[19,20,21,22,23,24]$. However, in case of vitiligo poorer QOL is seen in young patients [25].

The present study showed that, the Mean DLQI score of the female patients are more than that compared with the male patients. However, there is no statistically significant correlation between Gender \& DLQI score $(P=0.2828)$ in the present study. The study by Rajashekar TS et al, had also mentioned that DLQI scores compared between males and females does not show any statistical significance [18].

The least duration of disease in the present study was less than 10 weeks \& the highest duration was more than 60 weeks. In the present study, it was found that the DLQI score had a positive correlation with duration, that is QOL is more impaired in TC patients if the duration of the disease is more. Similar findings were reported in the study conducted by Rajashekar TS et al [18]. The minimum body surface area involved was $<2 \%$ and the maximum was $>10 \%$ in the present study.

The present study has also shown that DLQI score has a positive correlation with the body surface area involvement, that is QOL in TC patients is more hampered if the body surface area involved is more. Rajashekar TS et al, also found that and if the body surface area involved is more there is more adverse effect on the quality of life [18].

In a the study conducted by Patro $\mathrm{N}$ et al the overall effect on the QoL was moderate (score 6-10) in case of patients presenting with $\leq 6$ months duration of lesions \& patients with $\leq 10 \%$ BSA affected [10] In the same study there was a very large effect on QOL (score 11-20) in case of patients having $>6$ months duration of lesions \& patients with $>10 \%$ BSA affected [10].

\section{Limitations}

The present study included 328 patients keeping in mind the time constraints. This sample size could have been increased in view of the massive number of patients who are affected by TC at present. Multicentric large studies are required which may throw more light on the effects of TC on QOL.
Moreover, the present study could not assess the effect of TC separately on each of the six dimensions of the DLQI namely, symptoms and feelings, daily activities, leisure, work and school, personal relationships, and treatment. Effect due to TC on the QOL of patients less than 16 years also could not be assessed as the DLQI questionnaire is meant only for persons older than 16 years.

\section{Conclusion}

Presently lots of people in our country are affected by TC. Treatment of cutaneous dermatophytosis is becoming difficult day by day. Dermatologists are searching for ways to fight this challenge [C].

The adverse effects on QOL can be avoided if TC can be prevented. The adverse effects on QOL can be reduced if TC can be detected early and treated early. A study conducted in Mangalore by D'Souza MJ also mentioned that awareness must be increased so that early diagnosis \& treatment can be done [2].

There must be more efforts on the part of all concerned to increase awareness to stop the spread of the disease and regarding the prevention of the disease. Serious steps must also be taken for finding out efficient and patient friendly remedies.

Lots of research are required for developing an effective management for TC. A clear idea about the extent of effect on QOL due to TC will certainly boost further efforts for a better overall management of the disease.

\section{What this study adds to existing knowledge?}

Data regarding the effect of TC on the QOL is not easily available. There are only a few studies which have dealt with this serious issue. This study shows that the effect of TC on QOL is profound.

Features like duration of disease and extent of body surface area involvement have important impact on the QOL of the patients affected by TC.

\section{Author's contributions}

Dr. Nirmalya Kumar Das: Concept, study design, Manuscript preparation, data analysis.

Dr. Suchibrata Das: Data analysis, Manuscript correction. 


\section{Reference}

01. WHOQOL Group. Development of the World Health Organization WHOQOL-BREF QOL assessment. Psychol Med. 1998;28(3)551-558. [Crossref]

02. Halioua B, Bemmont MG, Lunel F. QOLin Dermatology. Int J Dermatol. 2000;39;801-806. [Crossref]

03. Verma S, Madhu R. The great Indian epidemic of superficial dermatophytosis- An appraisal. Indian J Dermatol. 2017;62(3)227-236.

doi: 10.4103/ijd.IJD_206_1 [Crossref]

04. D'Souza MJ. Awareness of Risk Factors for Dermatophytoses and its impact on QOL among adults in Mangalore- A Cross-sectional study. IOSR J Dent Med Sci (IOSR-JDMS). 2018;17(6)64-70. doi: $10.9790 / 0853-1706016470$ [Crossref]

05. Finlay AY, Khan GK. Dermatology Life Quality Index (DLQI)- a simple practical measure for routine clinical use. Clin Exp Dermatol. $1994 ; 19(3) 210-216$.

doi: $10.1111 / j .1365-2230.1994 . t b 01167 . x$ [Crossref]

06. Yeung H, Takeshita J, Mehta NN, Kimmel SE, Ogdie A, Margolis DJ, et al. Psoriasis severity and the prevalence of major medical comorbidity- a population-based study. JAMA Dermatol. 2013;149(10)1173-1179.

doi: 10.1001/jamadermatol.2013.5015 [Crossref]

07. Dogra S, Narang T. Emerging atypical and unusual presentations of dermatophytosis in India. Clin Dermatol Rev. 2017;1(3)12-18. doi: 10.4103/CDR.CDR_39_17 [Crossref]

08. Weitzman I, Summerbell RC. The dermatophytes. Clin MicrobiolRev. 1995;8(2)240-259.

doi: $10.1128 /$ CMR.8.2.240 [Crossref]

09. Sahoo AK, Mahajan R. Management of tinea corporis, tinea cruris, and tinea pedis- A comprehensive review. Indian Dermatol Online J. $2016 ; 7(2) 77-86$.

doi: 10.4103/ 2229-5178.178099 [Crossref]
10. Patro N, Panda M, Jena AK. The Menace of Superficial Dermatophytosis on the QOLof Patients Attending Referral Hospital in Eastern India- A Cross-sectional Observational Study. Indian Dermatol Online J. 2019;10(3)262-266. doi: 10.4103/idoj.IDO]_342_18 [Crossref]

11. Dogra S, Uprety S. The menace of chronic and recurrent dermatophytosis in India- Is the problem deeper than we perceive?. Indian Dermatol Online J. 2016;7(2)73-76. doi: $10.4103 / 2229-5178.178100$ [Crossref]

12. Panda S, Verma S. The menace of dermatophytosis in India- The evidence that we need. Indian J Dermatol Venereol Leprol. 2017;83(3)281-284.

doi: 10.4103/ijdvl.IJDVL_224_17 [Crossref]

13. Mohanty JC, Mohanty SK, Sahoo RC, Sahoo A, Praharaj $\mathrm{N}$. Incidence of dermatophytosis in Orissa. Indian J Med Microbiol. 1998;16(2)7880.

[Crossref]

14. Singh S, Beena PM. Profile of dermatophyte infections in Baroda. Indian J Dermatol Venereol Leprol. 2003;69(4)281-283.

[Crossref]

15. Bindu V, Pavithran K. Clinico-mycological study of dermatophytosis in Calicut. Indian J Dermatol Venereol Leprol. 2002;68(5)259-261.

[Crossref]

16. Peerapur BV, Inamdar AC, Pushpa PV, Srikant B. Clinicomycological study of dermatophytosis in Bijapur. Indian J Med Microbiol. 2004;22(4)273274.

[Crossref]

17. Sahoo AK, Mahajan R. Management of tinea corporis, tinea cruris, and tinea pedis- A comprehensive review. Indian Dermatol Online J. $2016 ; 7(2) 77-86$. doi: 10.4103/2229-5178.178099 [Crossref]

18. Rajashekar TS, Nandigonnanavar S, Kuppuswamy SK, Madhavi GS. Dermatology life quality index in patients with persisting and recurrent dermatophytoses. Int J Res Dermatol. 2019;5(1)139-143.

doi: 10.18203/issn.2455-4529.IntJResDermatol201 90233 [Crossref] 
19. Abedini R, Hallaji Z, Lajevardi V, Nasimi M, Khaledi MK, Tohidinik HR. Quality of life in mild and severe alopecia areata patients. Int J Womens Dermatol. 2018;4(2)91-94.

doi: 10.1016/j.ijwd.2017.07.001 [Crossref]

20. Al-Mutairi N, Eldin ON. Clinical profile and impact on quality of life- Seven years experience with patients of alopecia areata. Indian J Dermatol Venereol Leprol. $2011 ; 77(4) 489-493$.

doi: $10.4103 / 0378-6323.82411$ [Crossref]

21. Zhang M, Zhang N. Quality of life assessment in patients with alopecia are at a and androgenetic alopecia in the People's Republic of China. Dovepress. 2017;11;151-155.

doi: $10.2147 /$ PPA.S121218 [Crossref]

22. Hazarika N, Rajaprabha RK. Assessment of life quality index among patients with acne vulgaris in a suburban population. Indian J Dermatol. 2016;61(2)163-168.

doi: $10.4103 / 0019-5154.177758$ [Crossref]
23. Raddadi AA, Jfri A, Samarghandi S, Matury N, Habibullah T, Alfarshoti $M$, et al. Psoriasiscorrelation between severity index (PASI) quality of life index (DLQI) based on type of treatment. J Dermatol Surg. 2016;20(1)15-18. doi: 10.1016/j.jdds.2015.05.002 [Crossref]

24. Nayak PB, Girisha BS, Noronha TM. Correlation between disease severity, family income, and quality of life in psoriasis- A study from South India. Indian Dermatol Online J. 2018;9(3)165169.

doi: 10.4103/idoj.IDOJ_250-17 [Crossref]

25. Hedayat K, Karbakhsh M, Ghiasi M, Goodarzi A, Fakour Y, Akbari Z, et al. Quality of life in patients with vitiligo- a cross-sectional study based on Vitiligo Quality of Life index (VitiQoL). Health Qual Life Outcomes. 2016;14;1-9.

doi: 10.1186/s12955-016-0490-y [Crossref] 